\title{
Changes of calcitonin gene-related peptide and other serological indicators in vestibular migraine patients
}

\author{
Xinyi Liu ${ }^{1}$, Yonghui Pan ${ }^{1 *}$, Jingjing Wang ${ }^{2}$, Lei Zhang ${ }^{1}$, Junli Zhang ${ }^{1}$
}

\begin{abstract}
Objective: It aims to evaluate the diagnostic ability of CGRP and other blood indicators in vestibular migraine (VM) patients, and to explain the potential pathological effects of these biomarkers. The hypothesis of VM being a variant of migraine was examined. Methods: A total of $32 \mathrm{VM}$ patients, 35 migraine patients, and 30 healthy control subjects $(\mathrm{HC})$ were selected for this cross-sectional study. Detailed statistics on demographic data, clinical manifestations, calcitonin gene-related peptide (CGRP) and common clinical laboratory indicators were measured within 24 hours from the onset of the conditions. Receptor operating characteristic (ROC) curve and area under the curve (AUC) were analyzed for biomarkers. The risk factors of $\mathrm{VM}$ and migraine were determined through univariate and multivariate analyses. Results: Compared with HC, serum CGRP levels $(p(\mathrm{VM})=0.012, p($ Migraine $)=0.028)$ increased and $\mathrm{Mg}^{2+}$ levels $(p(\mathrm{VM})<0.001, p($ Migraine $)<0.001)$ deceased in VM patients and migraine patients. In multiple logistic regression, VM was correlated with CGRP [odds ratio $(O R)=1.07 ; 95 \%$ confidence interval $(\mathrm{Cl}), 1.02$ $1.12 ; P=0.01$ ] and $\mathrm{Mg}^{2+}$ [odds ratio $(O R)=0.03 ; 95 \% \mathrm{Cl}, 0.07-0.15 ; P$ $<0.001)$ ]. Migraine was correlated with CGRP [odds ratio $(O R)=1.07$; $95 \% \mathrm{Cl}, 1.02-1.12 ; P=0.01$ ] and $\mathrm{Mg}^{2+}$ [odd ratio $(O R=0.01 ; 95 \% \mathrm{Cl}$, $0-0.02 ; P<0.001)] . \mathrm{Mg}^{2+}$ discriminated good differentiation between VM and migraine groups, with AUC of $0.649(95 \% \mathrm{Cl}, 0.518$ to 0.780$)$. The optimal threshold for $\mathrm{Mg}^{2+}$ to diagnose VM was 0.805 . Conclusions: This study demonstrated that CGRP and $\mathrm{Mg}^{2+}$ may be promising laboratory indicators to discriminate $\mathrm{HC}$ from $\mathrm{VM} /$ migraine, while $\mathrm{Mg}^{2+}$ may be uded as a discriminator between VM and migraine.
\end{abstract}

\section{Keywords}

calcitonin gene-related peptide; vestibular migraine; magnesium lon; trigeminovascular system

Received 17 May 2021 accepted 30 June 2021

\section{Introduction}

Vestibular migraine (VM) is considered to be the combination of vertigo, dizziness, or balance disorders characteristic of migraine[1-2]. The lifetime prevalence of VM is estimated to be approximately $1 \%[3]$. It is the most common main cause of episodic vertigo and the second frequent cause of overall vertigo[4]. In 2012, the Barany Society and the International Headache Society[5] jointly published the first diagnostic criteria consensus. The symptoms of VM include spontaneous and positional vertigo, ataxia, head movement vertigo/dizziness, nausea and vomiting[6]. The duration of VM episodes varies from a few seconds to a few days, and $74 \%$ of patients independently experience headache symptom[3]. In addition, patients may develop vestibular symptoms due to visual stimulation or head movement. Although the above described

\author{
1 The First Affiliated Hospital of Harbin Medical University, Harbin 150001, China \\ 2 The First People's Hospital of Shangqiu, Shangqiu 476005, China
}

*Corresponding author Yonghui Pan, E-mail: aigui1993@126.com changes in symptoms are accurate, it is still difficult to confirm the diagnosis of VM[7]. Therefore, it is necessary to find effective and reliable biomarkers for clinical diagnosis and explore potential pathological mechanisms.

Neuroimaging studies demonstrated that the related changes in VM patients include cognitive-behavioral network (vestibulothalamo-cortical circuit), interoceptive network (parabrachial nucleus, amygdaloid nucleus, the hypothalamus, and the insular cortex) and neurological sensorimotor performance network (the locus coeruleus and the dorsal raphe nucleus)[8]. Cognitive behavior network showed prominent expression of calcitonin gene-related peptide (CGRP) receptors in rats[9]. Interoceptive network showed large concentrations of CGRP immunoreactive neurons[10]. Neurological sensorimotor performance network may be the target of CGRP 
antagonist[11]. Therefore, it is reasonable to speculate that CGRP has diagnostic value for the pathogenesis of VM. However, to date, no studies have evaluated the changes in serum CGRP in VM patients.

CGRP is a neuropeptide, consisting of 37 amino acids, and predominantly expressed in the nervous system and is widely distributed in the central and peripheral nervous systems[12-13]. It induces vascular responses and enhances, in general, the excitatory actions by potentiating the release of substance $P$ as well as excitatory amino acids from primary afferent fibers[14]. Furthermore, it triggers inflammatory tissue reactions, known as neurogenic inflammation[15]. CGRP mediates vascular responses by inducing the endothelium-dependent and endothelium-independent pathways[16]. Plasma extravasation caused by vasodilation recruits white blood cells and mast cell degranulation, thus causing nervous inflammatory response to the nervous system[15]. CGRP level has been shown to play a causative role in migraine attack. Accordingly, Sarchielli et al[17] detected a specific increase in the release of CGRP in the external jugular vein during an acute migraine attack.

Therefore, we aimed to study whether the changes in CGRP levels in VM patients have diagnostic value. To help diagnosis, some clinical indicators (eg, blood pressure, lipids, blood glucose etc.) were also detected. For this purpose, we screened blood test indicators and serum CGRP for patients with VM and migraine and investigated the potential correlation between these indicators and clinical parameters. In addition, it is generally believed that VM is a variant of migraine[1]. As many as $50 \%$ of migraine patients experience vertigo or dizziness, and the average duration of dizziness after migraine attack is 6 years in VM patients[18]. Due to the high correlation between VM and migraine, migraine patients were also enrolled in the present study for comparisons of similarities and differences.

\section{Methods}

\subsection{Study population}

This study was approved by the Research Ethics Committee of the First Affiliated Hospital of Harbin Medical University, and all participants signed informed consent form. Totally, 30 health control (HC) subjects were recruited through community health screening and media advertisements, and 32 VM patients and 35 migraine patients were recruited from the Department of Neurology, Affiliated Hospital of Harbin Medical University. All individuals were referred to neurologists (H.A.) to ensure that they fulfilled the entry criteria. There was no statistical difference in the basic conditions of subjects such as gender and age. Patients who met the diagnostic criteria for VM and migraine according to the 2013 International Classification of Headache Disorders (ICHD)(13) and those with favorable compliance and informed consent were recruited. Subject exclusion standard includes other types of dizziness (benign paroxysmal vertigo, Meniere's disease, vestibular neuritis, etc.) or headache (Tension headache, infectious headache, etc.), other chronic medical conditions (such as cerebrovascular disease, cancer, hypothyroidism, hyperthyroidism, Parkinson's disease, hypertension, etc.), or patients with alcohol, caffeine abuse, analgesic drugs over 2 weeks.

\subsection{Clinical features}

Demographic data (age and gender), risk factors (systolic blood pressure, diastolic blood pressure, current smoking and drinking status), and clinical symptoms of VM and migraine patients (frequency, duration, accompanying symptoms and comorbidities) were recorded at admission. The subjects' fasting venous blood samples were collected within 24 hours after the admission or outpatient clinic, and the samples were sent to our hospital's clinical laboratory for routine blood examination within 1-2 hours (measured variables include red blood cell, platelet, blood glucose, cholesterol and triglyceride).

\subsection{ELISA}

After the recruitment within $24 \mathrm{~h}$, anterior venous blood was immediately drawn and collected into the anticoagulation tube. The samples were centrifuged and stored at $-80^{\circ} \mathrm{C}$ until the subsequent assay. All fasting blood was coded, and investigators did not know in advance patients' blood samples. Serum CGRP was determined using a commercial ELISA kit (USCN Life Science Inc., Hubei, China) following manufacturer's instructions strictly. Absorption levels were measured with a spectrophotometer from BioRad (Hercules, CA). The detection limit of the assay was $4.3 \mathrm{pg} / \mathrm{mL}$.

\subsection{Statistical analysis}

All statistical analyses were performed with SPSS 22.0 Software. Kolmogorov-Simirnov test analysis method and $Q-Q$ chart test were used to determine whether it is normally distributed. The data of all variables are normally distributed and expressed as mean \pm standard deviation (SD). Otherwise, median and inter-quartile ranges were considered. ANOVA analysis and Tukey's post hoc test were used to compare the differences among the three groups based on their distribution. For the clinical symptoms of VM and migraine patients, we used two-sample t-test and chi-square test to analyze the differences among groups. Subsequently, the independent factors of $\mathrm{VM} /$ migraine were selected by univariate and multivariate logistic regression analyses. The odds ratio (OR) and 95\% confidence interval $(\mathrm{Cl})$ were calculated. Finally, in order to determine the diagnostic accuracy of these biomarkers, receiver operating characteristic (ROC) curve was constructed to compare the area under ROC curve (AUC), the values of sensitivity and specificity with 95\% confidence internal $(\mathrm{Cl})$. Based on the sensitivity-specificity 
pairs of these ROC curves, Youden index (sensitivity+specificity-1) was maximized to determine the cut-off value. Statistically, $P$-value $<0.05$ is considered significant.

\section{Results}

The clinical characteristics of enrolled individuals were depicted in Table 1. The mean $( \pm S D)$ age of the VM patients was $52.52 \pm 8.06$ years, of which $20(62.5 \%)$ patients were women. The mean ( $\pm S D$ ) age of the migraine patients was 47.86 years \pm 9.00 years, of which $21(60 \%)$ patients were women. For risk factors, there were no significant differences with regard to smoking rates, drinking rates, systolic blood pressure and diastolic blood pressure among VM, migraine and $\mathrm{HC}$ groups $(P>0.05)$. With regard to laboratory test indicators, the median RBC, platelet, blood glucose, cholesterol and triglyceride counts were comparable among the three groups. Compared with $\mathrm{HC}$, the median serum CGRP was significantly higher in VM and migraine groups, while the median $\mathrm{Mg}^{2+}$ was significantly lower (Fig. 1). Compared with the migraine group (70.82 $\pm 10.90 \mathrm{pg} / \mathrm{mL}$ ), there was no significant difference in the median serum CGRP in the VM group $(70.45 \pm 12.27 \mathrm{pg} / \mathrm{mL})(P>0.05)$. In contrast, the median $\mathrm{Mg}^{2+}$ was significantly lower in the VM group $(0.76 \pm 0.07 \mathrm{mmol} / \mathrm{L})$ than in the migraine group $(0.81 \pm 0.07 \mathrm{mmol} / \mathrm{L})$ $(P=0.047)$.

For VM patients, the frequency number of dizziness and relief was approximately $1.34 \pm 0.86$ and $8.30 \pm 11.57$, respectively. VM patients were more prone to nausea $(75 \%)$ and vomiting $(56.25 \%)$ than other symptoms. In migraine patients, the frequency number of headaches was $2.14 \pm 1.14$ that was significantly more frequent $(P=0.002)$ than in VM patients by t-test. Similarly, the mitigation time of migraine patients was about $15.59 \pm 17.40$ hours, which was significantly different $(p=0.05)$ from that in VM patients. The accompanying symptoms in migraine patients also manifested nausea $(62.86 \%)$ and vomiting (40\%). Comorbidities enrolled in this study were illustrated in the Table 2 . There were no significant differences in arterial hypertension and depression $(p>0.05)$.

Since the serological indicators demonstrated a preference for the patient groups, it is necessary to explore whether these indicators could be used as independent risk factors for VM/migraine (see Table 3). Therefore, univariate logistic regression analysis was used to determine odds ratio (OR). Age and frequency were found positively correlated with the occurrence of $\mathrm{VM}$, while $\mathrm{Mg}^{2+}$ was negatively correlated with the risk of the occurrence of VM. The potential of predicting the risk related to gender, smoking, drinking, duration, nausea, vomiting, tinnitus, defecation, and serum CGRP was unclear. In addition, the frequency was positively correlated with the occurrence of migraine. The potential of predict risk related to other indicators was unclear. Multivariate logistic regression analysis showed that CGRP $(O R=1.07,95 \%$ confidence interval $[C l]: 1.02-$ $1.12, P=0.01)$ and $\mathrm{Mg}^{2+}(O R=0.03,95 \% \mathrm{Cl}: 0.07-0.15, P<0.001)$

Table 1. Demographical, physiological, and clinical characteristics of vestibular migraine (VM) patients, migraine patients and control healthy ( $n=97$ )

\begin{tabular}{|c|c|c|c|c|}
\hline Variables & $\mathrm{HC}(N=30)$ & Migraine $(N=35)$ & $\mathrm{VM}(N=32)$ & ANOVA $P$ \\
\hline \multicolumn{5}{|l|}{ Demographic characteristics } \\
\hline Gender (Male/Female) & $14 / 16$ & $14 / 21$ & $12 / 20$ & $0.703^{d}$ \\
\hline Age (years) & $49.90 \pm 7.25$ & $47.86 \pm 9.00$ & $52.52 \pm 8.06$ & 0.068 \\
\hline \multicolumn{5}{|l|}{ Risk factors } \\
\hline Smoking(percentage) & $2(6.67)$ & $3(8.57)$ & $5(15.162)$ & 0.498 \\
\hline Drinking(percentage) & $2(6.67)$ & $3(8.57)$ & $4(12.5)$ & 0.746 \\
\hline Systolic blood pressure (mmHg) & $127.93 \pm 10.68$ & $126.43 \pm 15.89$ & $134.15 \pm 19.68$ & 0.118 \\
\hline Diastolic blood pressure $(\mathrm{mmHg})$ & $79.57 \pm 7.60$ & $78.54 \pm 13.79$ & $80.05 \pm 10.97$ & 0.732 \\
\hline \multicolumn{5}{|l|}{ Laboratory test indicators } \\
\hline CGRP (pg/mL) & $62.41 \pm 11.46$ & $70.82 \pm 10.90^{b}$ & $70.45 \pm 12.27^{\mathrm{c}}$ & $0.007^{*}$ \\
\hline $\operatorname{Mg}^{+}(\mathrm{mmol} / \mathrm{L})$ & $0.88 \pm 0.06$ & $0.81 \pm 0.07^{b}$ & $0.76 \pm 0.07^{\mathrm{ac}}$ & $<0.001^{*}$ \\
\hline Red blood cell $\left(10^{12} / \mathrm{L}\right)$ & $4.68 \pm 0.49$ & $4.71 \pm 0.51$ & $4.72 \pm 0.52$ & 0.444 \\
\hline Platelet $\left(10^{9} / \mathrm{L}\right)$ & $230.44 \pm 70.21$ & $253.94 \pm 54.79$ & $254.36 \pm 52.42$ & 0.210 \\
\hline Blood glucose (mmol/L) & $5.73 \pm 0.46$ & $5.69 \pm 1.21$ & $5.31 \pm 1.35$ & 0.264 \\
\hline Cholesterol (mmol/L) & $5.10 \pm 0.95$ & $4.96 \pm 1.06$ & $5.22 \pm 0.73$ & 0.521 \\
\hline Triglyceride (mmol/L) & $1.85 \pm 1.40$ & $1.91 \pm 1.50$ & $1.76 \pm 1.28$ & 0.817 \\
\hline
\end{tabular}

Data are expressed as mean $\pm S D$. Abbreviations: CGRP, Calcitonin gene-related peptide; $\mathrm{Mg}^{2+}$, Magnesium ions. Data were analyzed by one-way ANOVA and Tukey's post hoc test. ${ }^{a}, P<0.05$ VM vs. control; ${ }^{b} P<0.05$ migraine patients vs. control; ${ }^{\circ}, P<0.05$ VM vs. migraine patients; ${ }^{d}$, Chi-square test; ${ }^{*}$, ANOVA $P<0.05$. 

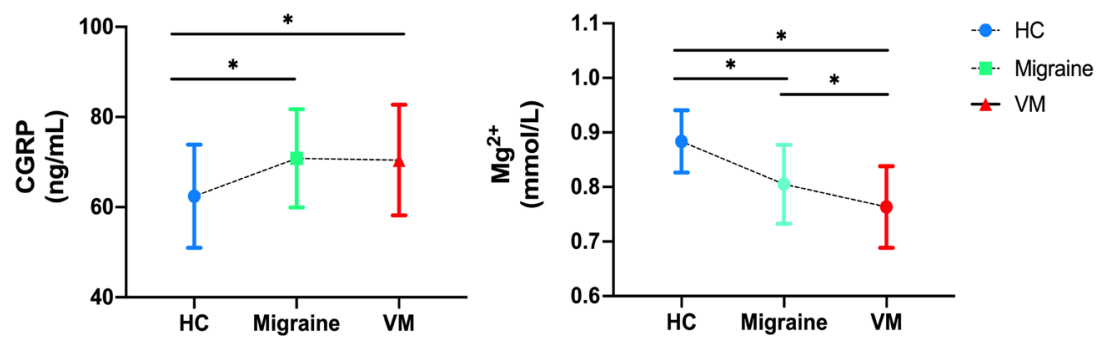

Fig. 1

The CGRP and $\mathrm{Mg}^{2+}$ levels in vestibular migraine patients, migraine patients and healthy controls

The error bars indicate standard deviation. ${ }^{*}, p<0.05$.

Abbreviation: CGRP, calcitonin gene related peptide; $\mathrm{Mg}^{2+}$, Magnesium ions.

Table 2. Summary of clinical characteristics of the VM and migraine patients included in the present study

\begin{tabular}{|c|c|c|c|}
\hline Variables & Migraine $(N=35)$ & VM $(N=32)$ & $P$ value \\
\hline \multicolumn{4}{|l|}{ Symptoms } \\
\hline Frequency (number of times) & $2.14 \pm 1.14$ & $1.34 \pm 0.86$ & $0.002^{*}$ \\
\hline Duration(hours) & $15.59 \pm 17.40$ & $8.30 \pm 11.57$ & $0.050^{*}$ \\
\hline \multicolumn{4}{|l|}{ Accompanying symptoms } \\
\hline Nausea & $22(62.86)$ & $24(75)$ & $0.285^{\mathrm{b}}$ \\
\hline Vomiting & $14(40)$ & $18(56.25)$ & $0.183^{b}$ \\
\hline Tinnitus & $0(0)$ & $5(15.63)$ & $0.015 b^{*}$ \\
\hline Blurred vision & $7(20)$ & $3(9.4)$ & $0.223^{b}$ \\
\hline Defecation & $0(0)$ & $1(3.1)$ & $0.292^{b}$ \\
\hline \multicolumn{4}{|l|}{ Comorbidities } \\
\hline Arterial hypertension & $8(22.86)$ & $14(43.75)$ & $0.069 b$ \\
\hline Depression & $4(11.43)$ & $2(6.25)$ & $0.458 b$ \\
\hline
\end{tabular}

Data are expressed as mean $\pm S D$. Values are shown as number (percentage) except where specified. * $P<0.05 ;{ }^{a}$ two sample $t$-test; ${ }^{b}$ Chi-squared test.

were correlated with the risk of VM. Similarly, CGRP $(O R=1.07$, $95 \% \mathrm{Cl}, 1.02-1.12, p=0.01)$ and $\mathrm{Mg}^{2+}(\mathrm{OR}=0.01,95 \% \mathrm{Cl}: 0-0.02$, $p<0.001)$ were correlated with the risk of migraine.

The ROC curves and optimal threshold values of serum CGRP and $\mathrm{Mg}^{2+}$ for the diagnosis of $\mathrm{VM} /$ migraine were shown in Fig. 2 and Table 4. The performance of $\mathrm{Mg}^{2+}$ ([VM vs $\mathrm{HC}$ ]: $\mathrm{AUC}=0.907$, 95\% Cl:0.837-0.978, $P<0.001$; [Migraine vs $\mathrm{HC}$ ]: $\mathrm{AUC}=0.812$, 95\% Cl:0.706-0.919, $P<0.001$; [VM vs Migraine]: $A U C=0.649$, $95 \% \mathrm{Cl}: 0.518-0.780, P=0.035)$ diagnoses in the three groups was significantly better than CGRP ([VM vs $\mathrm{HC}]$ : $A U C=0.680,95 \% \mathrm{Cl}$ : 0.545-0.815, $P=0.016$; [Migraine vs $\mathrm{HC}$ ]: $\mathrm{AUC}=0.694,95 \% \mathrm{Cl}$ : $0.563-0.825, P=0.009$; [VM vs Migraine]: $\mathrm{AUC}=0.531,95 \% \mathrm{Cl}$ : $0.391-0.670, P=0.531$ ). Compared with $\mathrm{HC}$, the cutoff value of $\mathrm{Mg}^{2+}$ in VM and migraine was 0.805 and 0.885 , respectively. The cutoff value of CGRP in VM and migraine was 54.15 and 54.365 , respectively. For VMs and migraines, the Youden index of $\mathrm{Mg}^{2+}$ and CGRP was 0.244 and 0.132 , respectively.

\section{Discussion}

In this study, we determined the serum levels of CGRP for VM patients and identified its diagnostic value. The serum CGRP increased during $\mathrm{VM} /$ migraine attacks, whereas $\mathrm{Mg}^{2+}$ decreased significantly. CGRP and $\mathrm{Mg}^{2+}$ may serve as potential VM diagnostic markers. As expected, the levels of CGRP and $\mathrm{Mg}^{2+}$ in migraine patients performed the same trend as in VM. For the comparison between VM and migraine, $\mathrm{Mg}^{2+}$ was more effective than CGRP as a biomarker for detecting VM.

Our main finding in the present study is that serum CGRP levels significantly increased in migraine and VM patients compared with those in $\mathrm{HCs}$, while there was no significant difference in CGRP levels between VM and migraine patients. Previous studies have confirmed that serum CGRP in migraine patients increases during the onset, and decreases after experiencing effective treatment[19-20]. Furthermore, several novel CGRP 
Table 3. Univariate and multivariate logistic regression analyses between VM patients and migraine patients

\begin{tabular}{|c|c|c|c|c|c|c|c|c|}
\hline \multirow{3}{*}{ Variables } & \multicolumn{4}{|c|}{ VM } & \multicolumn{4}{|c|}{ Migraine } \\
\hline & \multicolumn{2}{|c|}{ Univariate } & \multicolumn{2}{|c|}{ Multivariate } & \multicolumn{2}{|c|}{ Univariate } & \multicolumn{2}{|c|}{ Multivariate } \\
\hline & OR (95\% Cls) & $P$ value & OR (95\% Cls) & $P$ value & OR (95\% Cls) & $P$ value & OR (95\% Cls) & $P$ value \\
\hline Age & $\begin{array}{c}1.06 \\
(1.01-1.12)\end{array}$ & $0.03^{*}$ & $\begin{array}{c}1.04 \\
(0.98-1.11)\end{array}$ & 1.04 & $\begin{array}{c}0.95 \\
(0.90-1.00)\end{array}$ & 0.06 & $\begin{array}{c}0.97 \\
(0.91-1.03)\end{array}$ & 0.35 \\
\hline Gender & $\begin{array}{c}1.216 \\
(0.51-2.91)\end{array}$ & 0.66 & $\begin{array}{c}1.52 \\
(0.54-4.08)\end{array}$ & 1.52 & $\begin{array}{c}1.04 \\
(0.45-2.43)\end{array}$ & 0.93 & $\begin{array}{c}1.30 \\
(0.48-3.55)\end{array}$ & 0.61 \\
\hline Current smoking & $\begin{array}{c}0 \\
(0-)\end{array}$ & 0.99 & $\begin{array}{c}1.012 \\
(0.26-2.66)\end{array}$ & 0.11 & $\begin{array}{c}5.63 \\
(0.56-56.3)\end{array}$ & 0.14 & $\begin{array}{c}2.53 \\
(0.25-25.77)\end{array}$ & 0.43 \\
\hline Current drinking & $\begin{array}{c}0.48 \\
(0.05-4.52)\end{array}$ & 0.52 & $\begin{array}{c}0.84 \\
(0.05-25.77)\end{array}$ & 0.43 & $\begin{array}{c}2.77 \\
(0.44-17.42)\end{array}$ & 0.28 & $\begin{array}{c}2.53 \\
(0.25-25.77)\end{array}$ & 0.44 \\
\hline $\begin{array}{c}\text { Frequency } \\
\text { (number of times) }\end{array}$ & $\begin{array}{c}1.43 \\
(1.24-1.78)\end{array}$ & $0.01^{*}$ & & - & $\begin{array}{c}2.31 \\
(1.29-4.16)\end{array}$ & $0.01^{*}$ & & - \\
\hline $\begin{array}{l}\text { Duration } \\
\text { (hours) }\end{array}$ & $\begin{array}{c}0.96 \\
(0.92-1.00)\end{array}$ & 0.07 & & - & $\begin{array}{c}1.04 \\
(1.00-1.09)\end{array}$ & 0.07 & & - \\
\hline Nausea & $\begin{array}{c}1.57 \\
(0.54-4.53)\end{array}$ & 0.41 & & - & $\begin{array}{c}0.64 \\
(0.22-1.85)\end{array}$ & 0.41 & & - \\
\hline Vomiting & $\begin{array}{c}1.93 \\
(0.73-5.10)\end{array}$ & 0.19 & & - & $\begin{array}{c}0.52 \\
(0.20-1.37)\end{array}$ & 0.19 & & - \\
\hline Tinnitus & $\begin{array}{c}1.12 \\
(0.32-3.89)\end{array}$ & 0.86 & & - & $\begin{array}{c}0.90 \\
(0.36-3.13)\end{array}$ & 0.86 & & - \\
\hline Defecation & $\begin{array}{c}2.27 \\
(0.20-26.27)\end{array}$ & 0.51 & & - & $\begin{array}{c}0.44 \\
(0.34-5.11)\end{array}$ & 0.51 & & - \\
\hline CGRP & $\begin{array}{c}1.01 \\
(0.98-1.05)\end{array}$ & 0.46 & $\begin{array}{c}1.07 \\
(1.02-1.12)\end{array}$ & $0.01^{*}$ & $\begin{array}{c}1.03 \\
(0.99-1.07)\end{array}$ & 0.11 & $\begin{array}{c}1.07 \\
(1.02-1.12)\end{array}$ & $0.01^{*}$ \\
\hline $\mathrm{Mg}^{2+}$ & $\begin{array}{c}0 \\
(0-0.002)\end{array}$ & $<0.001^{*}$ & $\begin{array}{c}0.03 \\
(0.07-0.15)\end{array}$ & $<0.001^{*}$ & $\begin{array}{c}0.15 \\
(0-21.76)\end{array}$ & 0.45 & $\begin{array}{c}0.01 \\
0(0-0.02)\end{array}$ & $<0.001^{*}$ \\
\hline
\end{tabular}

Note: $\mathrm{Cl}$, confidence interval; OR, odds ratio. CGRP, calcitonin gene-related peptide; $\mathrm{Mg}^{2+}$, Magnesium ions. ${ }^{*}, P<0.01$.
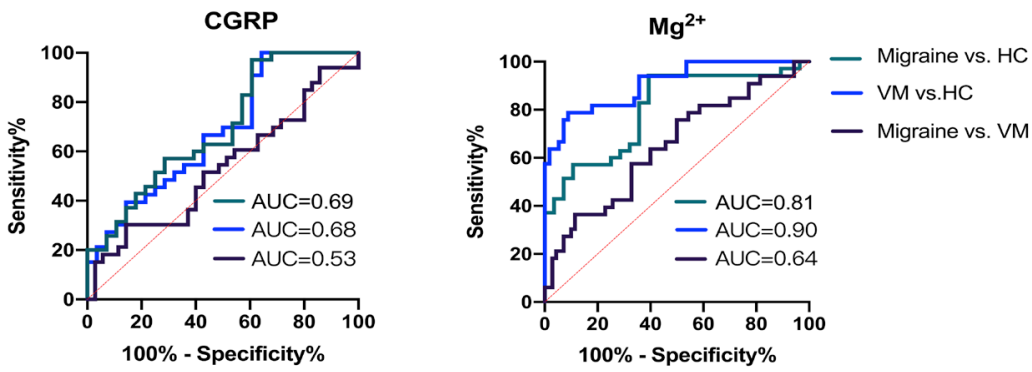

Fig. $2 \mathrm{ROC}$ curve by using CGRP and $\mathrm{Mg}^{2+}$ indicators to classify vestibular migraine patients, migraine patients and healthy controls

Abbreviation: AUC, area under curve; ROC, receiver operating characteristic curve; CGRP, calcitonin gene related peptide; $\mathrm{Mg}^{2+}$, Magnesium ions.

receptor antagonists have been confirmed to be effective in migraine treatment[21-22]. More and more evidences indicate that CGRP plays a key role in migraine pathogenesis[23-24], and the underlying mechanism mainly involves neurogenic inflammation[25-27]. During the attack of migraine, the neocortical extracellular release signal of cortical spreading depression (CSD) activates the trigeminal afferent, which would cause the trigeminal nerve vascular reflex mediated vasodilation in the meninges through the parasympathetic relay in the sphenopalatine ganglion[28]. In the meantime, the secretion of CGRP and other peptides from the axon collaterals of trigeminal ganglion cells triggers sterile inflammatory response. Some peptides can 
Table 4. ROC analysis results (AUC and Youden indices) for VM patients, migraine patients and control subjects

\begin{tabular}{|c|c|c|c|c|c|}
\hline Variables & $A U C$ value & $p$ value & $95 \% \mathrm{Cl}$ & Youden index & Optimal threshold \\
\hline \multicolumn{6}{|l|}{ CGRP } \\
\hline Migraine vs. HC & 0.694 & $0.009^{*}$ & $(0.563,0.825)$ & 0.364 & $55.655 \mathrm{ng} / \mathrm{ml}$ \\
\hline VM vs. HC & 0.680 & $0.016^{*}$ & $(0.545,0.815)$ & 0.357 & $54.15 \mathrm{ng} / \mathrm{ml}$ \\
\hline Migraine vs. VM & 0.531 & 0.663 & $(0.391-0.670)$ & 0.132 & $59.365 \mathrm{ng} / \mathrm{ml}$ \\
\hline \multicolumn{6}{|l|}{$\mathrm{Mg}^{2+}$} \\
\hline Migraine vs. HC & 0.812 & $<0.001^{*}$ & $(0.706-0.919)$ & 0.55 & $0.885 \mathrm{mmol} / \mathrm{l}$ \\
\hline VM vs. HC & 0.907 & $<0.001^{*}$ & $(0.837,0.978)$ & 0.687 & $0.805 \mathrm{mmol} / \mathrm{l}$ \\
\hline Migraine vs. VM & 0.649 & $0.035^{*}$ & $(0.518,0.780)$ & 0.244 & $0.805 \mathrm{mmol} / \mathrm{l}$ \\
\hline
\end{tabular}

Abbreviations: CGRP, Calcitonin gene-related peptide; $\mathrm{Mg}^{2+}$, Magnesium ions; AUC, Area Under Curve; Cl, Confidence interval.

modulate the microenvironment of meningeal nociceptors to sensitize peripheral nerve pathways and cause headaches[29], while CGRP could exert more long-term effects by regulating the expression of genes that can enhance nociceptive signals (such as purinergic receptors P2X3 and CGRP)[30]. However, as for VM, there is older evidence that patients with common migraine exhibit balance abnormalities in the interictal state[31-32]. Most importantly, a recent study with measurements during attacks shows a vestibulocerebellar pattern of balance impairment in migraine patients, which led to a conclusion that regarding central vestibular dysfunction, both migraine and VM may from a continuum with different degrees of vestibulocerebellar involvements[33]. These findings indicate that VM is associated with migraine. At present, the pathophysiological mechanism of VM is unclear. Evidence exists supporting that there is substantial overlap between the vestibular migraine pathway and the migraine pathway[34-35], including cognitive-behavioral network, interoceptive network, and neurological sensorimotor performance network, and these networks are all related to the enrichment of CGRP[36-38]. In particular, blood vessels, neurogenic inflammation and central nervous mechanisms are considered to be peripheral and central triggers of migraine and are presented in the central vestibular pathway[39] and inner ear[24-34]. The inner ear trigeminal nerve vascular reflex innervation is a component of the trigeminal nerve vascular reflex system[40], and thus, the innervation may be a potential site of the action of CGRP antagonists. In the present study, CGRP level increased in VM patients compared with HCs, which is consistent with previous studies. We therefore speculate that VM and migraine may share, at least partly, the same pathological mechanism.

Another unexpected finding of our study was that $\mathrm{Mg}^{2+}$ levels in VM and migraine patients significantly reduced. $\mathrm{Mg}^{2+}$ is a co-factor in more than 300 enzyme systems and is involved in several biochemical reactions, including protein synthesis, muscle and nerve function, and blood glucose control[41-43]. In the nervous system, $\mathrm{Mg}^{2+}$ can act as a calcium channel antagonist in neurons to prevent excessive activation of excitatory synapses and inhibit the signal transduction in pro-inflammatory cells[44]. Previous studies showed that cytoplasmic $\mathrm{Mg}^{2+}$ is reduced in migraine patients, and magnesium supplementation is beneficial for migraine patients without aura[45-46]. The reason may be that the lack of $\mathrm{Mg}^{2+}$ is related to CSD[47]. During CSD, substance $P$ and CGRP are released after magnesium deficiency and may act on sensory fibers to cause headache[48-49]. The lack of $\mathrm{Mg}^{2+}$ leads to uncontrollable NMDA glutamate receptors, thereby leading to pain, cerebral blood flow and nervous system disorders[50]. This study is the first report about correlation of $\mathrm{Mg}^{2+}$ level with VM patients. There is electrophysiological evidence that there are potential postsynaptic activities that are related to $\mathrm{N}$-methyl$\mathrm{d}$-aspartate receptors in the cochlear nerve-related nucleus and vestibular nucleus[51], which is very important for the vestibular reflex. This may be a piece of supporting evidence for the connection between $\mathrm{VM}$ and $\mathrm{Mg}^{2+}$. The difference in $\mathrm{Mg}^{2+}$ between VM and migraine may be caused by the discrepancy in response range and firing kinetics among neurons[2]. In addition, the mechanism by which $\mathrm{Mg}^{2+}$ regulates the inflammatory mediator signal transduction in VM patients remains yet to be studied.

The potential biomarker value of $\mathrm{VM}$ and migraine was determined. CGRP and $\mathrm{Mg}^{2+}$ could be used as effective reference biomarkers for $\mathrm{VM} /$ migraine. It is worth noting that $\mathrm{Mg}^{2+}$ could better distinguish VM from migraine. For the clinical diagnosis and treatment, it would be highly desirable to distinguish VM from migraine using $\mathrm{Mg}^{2+}$ indicator on one hand, and it should also be helpful for delineating the pathological mechanisms linking $\mathrm{Mg}^{2+}$ to $\mathrm{VM}$, on the other hand. Whether VM is a variant of migraine and what the triggers are for the uncorrelated timing of the occurrence of the two diseases merit future studies to elucidate.

Previous studies have shown that VM has a moderately positive correlation with the maximum temperature difference $(r=0.593, P$ 
$=0.042)[52]$. In addition, neurons that express CGRPa play a role in encoding heat and tonically cross-inhibit cold sensation[53]. Studies have shown that CGRP neuronal defects in mice produce enhanced behavioral responses on cold stimulation[54], and this cold hypersensitivity response may be mediated by TRPV1[55]. Consequently, it is imperative to study cold factors for the relevant biomarkers of VM patients. The findings of the present study therefore bear some implications in the frigid zone-related diseases and indicate the necessity to pay more attention to the possible influences of ambient temperature on VM patients.

Some limitations associated with the present study need to be acknowledged. Firstly, only CGRP levels were assessed upon admission. Assessing longitudinal changes in serum indicators levels could provide meaningful insights into the development of vestibular migraine. Secondly, since CGRP degrades rapidly, the assessment of CGRP levels within 24 hours of admission may have certain impacts on the results. Thirdly, VM may involve subjects who have several common migraine attacks with some rare vertigo attacks in between, as well as subjects who suffer from frequent vertigo attacks and rare migraine/headache attacks in between. Unfortunately, we only had five VM patients with headache symptoms, so it is not objective to evaluate changes in the indicators of overlap between VM and headache. We plan to resolve these limitations in our future work.

\section{Conclusion}

In summary, this study demonstrated that CGRP and $\mathrm{Mg}^{2+}$ may be promising laboratory indicators to discriminate $\mathrm{HC}$ from VM/ migraine, while $\mathrm{Mg}^{2+}$ can better distinguish VM from migraine.

\section{Ethical approval and informed consent}

This study was approved by the Research Ethics Committee of the First Affiliated Hospital of Harbin Medical University, and all participants signed informed consent form.

\section{Conflicts of interest}

No support, financial or otherwise, has been received from any organization that may have an interest in the submitted work. There are no other relationships or activities that could appear to have influenced the submitted work.

\section{Acknowledgments}

National Natural Science Foundation of China (No. 82071549), Key Program of the Natural Science Fund in Heilongjiang Province (No. ZD2019H006), and National Key Research \& Development Program of China (No. 2016YFC1307205).

\section{References}

[1] Li V, McArdle H, Trip S A. Vestibular migraine. BMJ, 2019; 366: 14213.

[2] Xia J, Kong W J, Zhu Y, et al. Intrinsic membrane properties of rat medial vestibular nucleus neurons and their responses to simulated vestibular input signals. Zhonghua $\mathrm{Er} \mathrm{Bi}$ Yan Hou Tou Jing Wai Ke Za Zhi, 2008; 43(10): 767-772.

[3] Neuhauser H K, Radtke A, Von Brevern M, et al. Migrainous vertigo: prevalence and impact on quality of life. Neurology, 2006; 67(6): 10281033.

[4] Fernandez M, Birdi J S, Irving G J, et al. Pharmacological agents for the prevention of vestibular migraine. Cochrane Database Syst Rev, 2015; 6: CD010600.

[5] Lempert T, Olesen J, Furman J, et al. Vestibular migraine: diagnostic criteria. J Vestib Res, 2012; 22(4): 167-172.

[6] Alghadir A H, Anwer S. Effects of vestibular rehabilitation in the management of a vestibular migraine: a review. Front Neurol, 2018; 9: 440.

[7] Zhou C, Zhang L, Jiang X, et al. A novel diagnostic prediction model for vestibular migraine. Neuropsychiatr Dis Treat, 2020; 16: 1845-1852.

[8] Cuccurazzu B, Halberstadt A L. Projections from the vestibular nuclei and nucleus prepositus hypoglossi to dorsal raphe nucleus in rats. Neurosci Lett, 2008; 439(1): 70-74.

[9] Warfvinge K, Edvinsson L. Distribution of CGRP and CGRP receptor components in the rat brain. Cephalalgia, 2019; 39(3): 342-353.
[10] Tajti J, Uddman R, Edvinsson L. Neuropeptide localization in the "migraine generator" region of the human brainstem. Cephalalgia, 2001; 21(2): 96-101.

[11] Tiller-Borcich J K, Capili H, Gordan G S. Human brain calcitonin gene-related peptide (CGRP) is concentrated in the locus caeruleus. Neuropeptides, 1988; 11(2): 55-61.

[12] Emeson R B, Hedjran F, Yeakley J M, et al. Alternative production of calcitonin and CGRP mRNA is regulated at the calcitonin-specific splice acceptor. Nature, 1989; 341(6237): 76-80.

[13] Tanaka M, Takeda N, Senba E, et al. Localization and origins of calcitonin gene-related peptide containing fibres in the vestibular endorgans of the rat. Acta Otolaryngol Suppl, 1989; 468: 31-34.

[14] Van Rossum D, Hanisch U K, Quirion R. Neuroanatomical localization, pharmacological characterization and functions of CGRP, related peptides and their receptors. Neurosci Biobehav Rev, 1997; 21(5): 649-678.

[15] Xanthos D N, Sandkuhler J. Neurogenic neuroinflammation: inflammatory CNS reactions in response to neuronal activity. Nat Rev Neurosci, 2014; 15(1): 43-53.

[16] De Hoon J N, Pickkers P, Smits P, et al., Calcitonin gene-related peptide: exploring its vasodilating mechanism of action in humans. Clin Pharmacol Ther, 2003; 73(4): 312-321.

[17] Sarchielli P, Pini L A, Zanchin G, et al., Clinical-biochemical correlates of migraine attacks in rizatriptan responders and non- 
responders. Cephalalgia, 2006; 26(3): 257-265.

[18] Hsu L C, Wang S J, Fuh J L. Prevalence and impact of migrainous vertigo in mid-life women: a community-based study. Cephalalgia, 2011; 31(1): 77-83.

[19] Han D. Association of serum levels of calcitonin gene-related peptide and cytokines during migraine attacks. Ann Indian Acad Neurol, 2019; 22(3): 277-281.

[20] Cernuda-Morollon E, Larrosa D, Ramon C, et al. Interictal increase of CGRP levels in peripheral blood as a biomarker for chronic migraine. Neurology, 2013; 81(14): 1191-1196.

[21] Olesen J, Diener H C, Husstedt I W, et al. Calcitonin gene-related peptide receptor antagonist BIBN 4096 BS for the acute treatment of migraine. N Engl J Med, 2004; 350(11): 1104-1110.

[22] Hoffmann J, Goadsby P J. New agents for acute treatment of migraine: cgrp receptor antagonists, inos inhibitors. Curr Treat Options Neurol, 2012; 14(1): 50-59.

[23] Villalon C M, Olesen J. The role of CGRP in the pathophysiology of migraine and efficacy of CGRP receptor antagonists as acute antimigraine drugs. Pharmacol Ther, 2009; 124(3): 309-323.

[24] Ho T W, Edvinsson L, Goadsby P J. CGRP and its receptors provide new insights into migraine pathophysiology. Nat Rev Neurol, 2010; 6(10): 573-582.

[25] Akerman S, Romero-Reyes M, Holland P R. Current and novel insights into the neurophysiology of migraine and its implications for therapeutics. Pharmacol Ther, 2017; 172: 151-170.

[26] Russo A F. Calcitonin gene-related peptide (CGRP): a new target for migraine. Annu Rev Pharmacol Toxicol, 2015; 55(1): 533-552.

[27] Olesen J, Burstein R, Ashina M, et al. Origin of pain in migraine: evidence for peripheral sensitisation. Lancet Neurol, 2009; 8(7): 679690.

[28] Akerman S, Holland P R, Summ O, et al. A translational in vivo model of trigeminal autonomic cephalalgias: therapeutic characterization. Brain, 2012; 135(Pt 12): 3664-3675.

[29] Burstein R, Jakubowski M, Garcia-Nicas E, et al., Thalamic sensitization transforms localized pain into widespread allodynia. Ann Neurol, 2010; 68(1): 81-91.

[30] Sixt M L, Messlinger K, Fischer M J. Calcitonin gene-related peptide receptor antagonist olcegepant acts in the spinal trigeminal nucleus. Brain, 2009; 132(Pt 11): 3134-3141.

[31] Rossi C, Alberti A, Sarchielli P, et al. Balance disorders in headache patients: evaluation by computerized static stabilometry. Acta Neurol Scand, 2005; 111(6): 407-413.

[32] Akdal G, Donmez B, Ozturk v, et al. Is balance normal in migraineurs without history of vertigo? Headache, 2009; 49(3): e419-e425.

[33] Anagnostou E, Gerakoulis S, Voskou P, et al. Postural instability during attacks of migraine without aura. Eur J Neurol, 2019; 26(2): 319-321.

[34] Balaban C D. Migraine, vertigo and migrainous vertigo: Links between vestibular and pain mechanisms. J Vestib Res, 2011; 21(6): 315-321.

[35] Balaban C D, Jacob R G, Furman J M. Neurologic bases for comorbidity of balance disorders, anxiety disorders and migraine: neurotherapeutic implications. Expert Rev Neurother, 2011; 11(3): 379-394.

[36] Halberstadt A L, Balaban C D. Serotonergic and nonserotonergic neurons in the dorsal raphe nucleus send collateralized projections to both the vestibular nuclei and the central amygdaloid nucleus.
Neuroscience, 2006; 140(3): 1067-1077.

[37] Goadsby P J, Lipton R B, Ferrari M D. Migraine--current understanding and treatment. N Engl J Med, 2002; 346(4): 257-270.

[38] De Lacalle S, Saper C B. Calcitonin gene-related peptide-like immunoreactivity marks putative visceral sensory pathways in human brain. Neuroscience, 2000; 100(1): 115-130.

[39] Richter F, Bauer R, Lehmenkuhler A, et al., Spreading depression in the brainstem of the adult rat: electrophysiological parameters and influences on regional brainstem blood flow. J Cereb Blood Flow Metab, 2008; 28(5): 984-994.

[40] May A, Goadsby P J. The trigeminovascular system in humans: pathophysiologic implications for primary headache syndromes of the neural influences on the cerebral circulation. J Cereb Blood Flow Metab, 1999; 19(2): 115-127

[41] Veronese N, Zanforlini B M, Manzato E, et al. Magnesium and healthy aging. Magnes Res, 2015; 28(3): 112-115.

[42] Arnaud M J. Update on the assessment of magnesium status. $\mathrm{Br}$ J Nutr, 2008; 99(Suppl 3): S24-S36.

[43] Volpe S L. Magnesium in disease prevention and overall health. Adv Nutr, 2013; 4(3): S378-S383.

[44] Lingam I, Robertson N J. Magnesium as a neuroprotective agent: a review of its use in the fetus, term infant with neonatal encephalopathy, and the adult stroke patient. Dev Neurosci, 2018; 40(1): 1-12.

[45] Köseoglu E, Talaslioglu A, Gönül A S, et al. The effects of magnesium prophylaxis in migraine without aura. Magnes Res, 2008; 21(2): 101-108.

[46] Lodi R, IOTTI S, Cortelli P, et al. Deficient energy metabolism is associated with low free magnesium in the brains of patients with migraine and cluster headache. Brain Res Bull, 2001. 54(4): 437-441. [47] Coan E J, Collingridge G L. Magnesium ions block an N-methyl$\mathrm{D}$-aspartate receptor-mediated component of synaptic transmission in rat hippocampus. Neurosci Lett, 1985; 53(1): 21-26.

[48] Myrdal U, Leppert J, Edvinsson L, et al. Magnesium sulphate infusion decreases circulating calcitonin gene-related peptide (CGRP) in women with primary Raynaud's phenomenon. Clin Physiol, 1994; 14(5): 539-546.

[49] Innerarity S. Hypomagnesemia in acute and chronic illness. Crit Care Nurs Q, 2000; 23(2): 1-19; quiz 87.

[50] Foster A C, Fagg G E. Neurobiology. Taking apart NMDA receptors. Nature, 1987; 329(6138): 395-396.

[51] Sato K, Momose-Sato Y. Optical detection of developmental origin of synaptic function in the embryonic chick vestibulocochlear nuclei. J Neurophysiol, 2003; 89(6): 3215-3224.

[52] Yuan $\mathrm{H}$, Liu H, Hui H F, et al. Climatic variations and vertigo diseases in outpatients clinic of ENT. Lin Chung Er Bi Yan Hou Tou Jing Wai Ke Za Zhi, 2021; 35(2): 101-104.

[53] McCoy E S, Taylor-Blake B, Street S E, et al., Peptidergic CGRPalpha primary sensory neurons encode heat and itch and tonically suppress sensitivity to cold. Neuron, 2013; 78(1): 138-151.

[54] McCoy E S, Zylka M J. Enhanced behavioral responses to cold stimuli following CGRPalpha sensory neuron ablation are dependent on TRPM8. Mol Pain, 2014; 10: 69.

[55] Nassini R, Materazzi S, Benemei S, et al. The TRPA1 channel in inflammatory and neuropathic pain and migraine. Rev Physiol Biochem Pharmacol, 2014; 167: 1-43. 